\title{
Role of Baclofen in Combination with Intensive Rehabilitation in Spastic Cerebral Palsy
}

\author{
Md Ruhul Amin'1, Sohely Rahman², Narayan Saha³, Md Shahadat Hossain , Md Jahidul \\ Islam $^{5}$, Monzur Ahmed ${ }^{6}$, Prasanta Kumar Chakraborty7, Ferdous Ara Islam ${ }^{8}$ \\ ${ }^{1}$ Assistant Professor, Department of Physical Medicine \& Rehabilitation, Dhaka Medical College Hospital, Dhaka, Bangladesh; \\ ${ }^{2}$ Professor \& Head, Department of Physical Medicine \& Rehabilitation, Dhaka Medical College, Dhaka, Bangladesh; \\ ${ }^{3}$ Associate Professor, Department of Paediatric Neurology, National Institute of Neurosciences \& Hospital, Dhaka, \\ Bangladesh; ${ }^{4}$ Associate Professor, Department of Physical Medicine \& Rehabilitation, Dhaka Medical College, \\ Dhaka, Bangladesh; ${ }^{5}$ Assistant Professor, Department of Physical Medicine \& Rehabilitation, National \\ Institute of Neuroscience, Dhaka, Bangladesh; ${ }^{6}$ Medical Officer, Department of Physical Medicine \& \\ Rehabilitation, National Institute of Neuroscience \& Hospital, Dhaka, Bangladesh; ${ }^{7}$ Medical officer, \\ Department of Physical Medicine \& Rehabilitation, National Institute of Neuroscience, Dhaka, \\ Bangladesh; ${ }^{8}$ Medical Officer, Department of Neurosurgery, National Institute of \\ Neurosciences \& Hospital, Dhaka, Bangladesh
}

Received on: 24 July 2014; Reviewed on: 26 September 2014; Published on: 1 January 2015

\begin{abstract}
Background: The treatment of cerebral palsy is multifactorial. Objective: In this study we find out the combined efficacy of baclofen and intensive rehabilitation in the treatment of spastic cerebral palsy. Methodology: This observational study was conducted over 30 patients in Dhaka Medical College Hospital from January 2011 to December 2011.The patient satisfying the inclusion and exclusion criteria was randomly enrolled in this study. They received Baclofen orally two times daily according to the body weight regularly in combination with intensive rehabilitation 1 hour daily five times a week for 24 weeks. All patients were followed up at 4 weeks interval and were evaluated for a total of 24 weeks. Result: Combination of Baclofen and intensive rehabilitation is effective in reducing tone in spastic cerebral palsy by using Modified Ashworth scale $(p<0.05)$. Combination of Baclofen and intensive rehabilitation is also effective in joint angle improvement in spastic cerebral palsy measured by physician rating scale crouch $(p<0.05)$ and foot contact, $(p<0.05)$ and also improvement in gross motor function $(p<0.05)$. Conclusion: For reduction of generalized spasticity regarding muscle tone, range of motion of the joint and improvement of gait in cerebral palsy patients, combination of Baclofen and intensive rehabilitation may be used. [J Natl Inst Neurosci Bangladesh 2015;1(1):18-21]
\end{abstract}

Keywords: Referral pattern, psychiatry, neurology

Corresponding author: Dr. Md. Ruhul Amin, MBBS, FCPS (Physical medicine \& rehabilitation), Assistant Professor, Department of Physical Medicine \& Rehabilitation, Dhaka Medical College Hospital, Dhaka, Bangladesh; Email: dr.ruhulamin73@yahoo.com

Conflict of interest: Authors declared no conflict of interest

Funding of the study: None

Contribution of the authors: MRA, SR, NS, MSH, MJI, MA, PKC, FAI were contributed from protocol preparation to data collection and have prepared the manuscript and revised by them.

How to cite this article: Amin MR, Rahman S, Saha N, Hossain MS, Islam MJ, Ahmed M, Chakraborty PK, Islam FA. Role of baclofen in combination with intensive rehabilitation in spastic cerebral palsy. J Natl Inst Neurosci Bangladesh 2015;1(1):18-21

\section{Introduction}

Neurological illness has been found associated with Cerebral Palsy (CP) describes a group of permanent disorders of the development of movement and posture, causing activity limitations that are attributed to nonprogressive disturbances that occurred in the developing fetal or infant brain. The motor disorders of cerebral palsy are often accompanied by disturbances of sensation, perception, cognition, communication, and behavior; by epilepsy, and by secondary musculoskeletal problems ${ }^{1}$. In a majority of cases, the predominant motor abnormality is spasticity $^{2}$.
Cerebral palsy is the most common childhood disability with a prevalence of 1.5 to 3 per 1000 live births ${ }^{3,4}$. However, in a study at Physical Medicine \& Rehabilitation Department of BSMMU 1.72\% patients were diagnosed as $\mathrm{CP}^{5}$. Spastic cerebral palsy is the most common type, accounting for $75 \%$ of cases which affects a large proportion of this population ${ }^{6}$. Spasticity is one of the common features of cerebral palsy as it contributes to limitations in body structure and function, leading to deformity ${ }^{7}$. Treating the spasticity component of the movement disorder might enable improvement in the performance, participation, and 
satisfaction in everyday activities of these children ${ }^{6}$. Treatment of spastic cerebral palsy includes physiotherapy along with antispastic medication. Available drugs that are used to treat spasticity include benzodiazepines, baclofen, alpha-adrenergic agonists (tizanidine, clonidine), dantrolene sodium, and gabapentine ${ }^{8}$. Baclofen is a GABA agonist that is used to reduce muscle tone. Intensive rehabilitation may be defined as 1 hourly intervention, 5 days a week, as opposed to a therapy sessions once a week or once every second week ${ }^{9}$. It consists of neurodevelopmental treatment (NDT), therapeutic exercises (TEs) and activities of daily living (ADL) training ${ }^{10}$. The aim of this study was to find out the efficacy of oral baclofen in combination with intensive rehabilitation in reducing spasticity in cerebral palsy.

\section{Methodology}

This observational study was done in the Department of Physical Medicine \& Rehabilitation, Dhaka Medical College Hospital and Department of Pediatrics, Dhaka Medical College Hospital. The total duration of study was from January 2011 to December 2011. All the spastic cerebral palsy patients seeking treatment in outpatient department of Physical Medicine \& Rehabilitation and Pediatrics, Dhaka medical college hospital were the reference population. From reference population, patients enrolled in the study who met the inclusion and exclusion criteria. Patients aged between 12 months to 12 years of both sexes; with disorder in the development of movement and posture presumably of cerebral origin started before 2 years of age, presence of spasticity associated with or characterized by increased tone reflexes, clonus or extensor plantar response, and delayed miles stones of development which is improving over time were included as study population. Those with mixed type of cerebral palsy; receiving systemic anti-spasticity medications or had received phenol and/or botulinum toxin type A injections; past surgical intervention that might interfere with ankle joint movement; neurodegenerative disorders, chromosomal abnormality such as Down syndrome, inborn errors of metabolism such as galactosemia and presence of comorbidity such as epilepsy were excluded from the study. Complete history and clinical examination were done for all enrolled patients. After taking written informed consent they were finally selected for the study. Intensive rehabilitation 1 hour daily for 5 days a week and oral baclofen corresponding to approximately $0.3 \mathrm{mg} / \mathrm{kg}$ a day in two divided doses was given for 24 weeks. Patients were first assessed with Modified Asworth Scale (MAS)39 based on muscle tone to determine the extent of spasticity. Then Physician Rating Scale40 to measure joint angle (crouch) specially by standard goniometer, 46 knee recurvatum, foot contact and overall functional status by Gross Motor Functional Classification System ${ }^{11}$. Then intervention was done by giving oral baclofen with intensive rehabilitation to reduce spasticity and uniform intensive rehabilitation protocol was applied which includes prone lying position, sitting balance in specialized sitting chair, range of motion exercise, stretching exercise, activities of daily living (ADL) training. After 4 weeks (1st follow up) during the continuation of drugs, patients were again assessed by principal investigator using before mentioned 3 scales and adverse effect of oral baclofen was recorded in followup sheet. After 8 weeks (2nd follow up) were again assessed by principal investigator using before mentioned 3 scales and adverse effect of oral baclofen was recorded in followup sheet. Then followup assessment was done every 4 weekly at 12 th week, 16th week, 20th week and lastly 24th week with continuing the drugs using same scales by principal investigator. Intensive rehabilitation was given by an experienced physiotherapist at the department of Physical Medicine \& Rehabilitation, Dhaka Medical College Hospital, Dhaka. After group allocation, baclofen was given according to following dose schedule. Oral baclofen was started with a very low dose (corresponding to approximately $0.3 \mathrm{mg} / \mathrm{kg}$ a day) in two divided doses. One hour intensive physiotherapy was done daily for 5 days a week. Activities included in each session were body alignment weight transfer in various positions, bimanual activities and facilitation sequences of movements. Ethical clearance has been obtained from the concerned authority to conduct the research work of study subjects. Data were collected through a pretested structured questionnaire. Data were processed and analyzed using SPSS (statistical package for social science) version 17. Test statistics used to analysis the data were chi square Test and student $\mathrm{T}$ test. The level of significance was set 0.05 and p-value of less than 0.05 was considered significant.

\section{Results}

A total of 30 patients were recruited to yield 21 male and 9 female. Mean age (months) was $37.4 \pm 4.9$. Mean weight was $13.0 \pm 2.5$ (Table 1$)$.

\section{Discussion}

In this study, 30 children with cerebral palsy were enrolled. At the baseline evaluation 4(13.3\%) were Modified Asworth Scale grade 3, 18(60.0\%) grade 4, 8(26.7\%) grade 5. After 6 months, spasticity was significantly reduced; $23(76.7 \%)$

\section{Table 1: Demographic characteristics}

\begin{tabular}{ll}
\hline Variables & Values \\
\hline Age & $37.4 \pm 4.9$ \\
Weight & $13.0 \pm 2.5$ \\
Gender & \\
- Male & $21(70 \%)$ \\
- Female & $9(30 \%)$ \\
\hline
\end{tabular}

children showed Modified Asworth Scale grade 0-1, $6(20.0 \%)$ were grade $2-3$ and $1(3.3 \%)$ grade $4-5$. Regarding Physician ratings scale, most of the severe and moderate 
angle for crouch gait at baseline in experienced more

Table 2: Modified Asworth Scale

\begin{tabular}{llllll}
\hline $\begin{array}{l}\text { Level } \\
\text { score }\end{array}$ & $\begin{array}{l}\text { Pretreatment } \\
\text { Level }\end{array}$ & $\begin{array}{l}\text { Score after } \\
\text { 3 month }\end{array}$ & $\begin{array}{l}\text { Score after } \\
\text { 6 month }\end{array}$ & $\begin{array}{l}\text { Chi Square test } \\
\text { P value }\end{array}$ \\
\hline 3 & $4(13.3 \%)$ & $0-1$ & $21(70.0 \%)$ & $23(76.7 \%)$ & $\mathrm{P}<0.00001 \mathrm{~S}$ \\
4 & $18(60 \%)$ & $2-3$ & $9(30.0 \%)$ & $6(20.0 \%)$ & $(\mathrm{P}<0.05)$ \\
5 & $8(26.7 \%)$ & $4-5$ & 0 & $1(3.3 \%)$ & \\
\hline
\end{tabular}

Table 3: Physician Rating Scale improvement in activities in daily life.

In a study Intermittent versus continuous physiotherapy in children with cerebral palsy- Christiansen et al ${ }^{14}$ reported that GMFM-66 score increased significantly in both intermittent and continuous group. Baclofen has been poorly studied in spasticity of cerebral origin with most studies evaluating efficacy in treating spasticity of spinal cord origin. Although no studies on the use of baclofen to treat children was found, it is still commonly recommended as a treatment option for children with spasticity ${ }^{15-16}$. Baclofen

\begin{tabular}{lllll}
\hline Physical rating scale & Pre treatment & $\begin{array}{l}\text { 3 Month after } \\
\text { treatment }\end{array}$ & $\begin{array}{l}\text { 6 Month after } \\
\text { treatment }\end{array}$ & $\begin{array}{l}\text { Chi Square test; } \\
\text { P value }\end{array}$ \\
\hline $\begin{array}{l}\text { Knee } \\
\text { Recurvatum }>5\end{array}$ & $1(3.3)$ & $0(0.0)$ & $0(0.0)$ & $\mathrm{X} 2=2.1802$ \\
$\begin{array}{l}\text { Recurvatum }<0-5 \\
\text { No Recurvatum }\end{array}$ & $4(13.3)$ & $5(16.7)$ & $4(13.3)$ & $\mathrm{P}=0.702 \mathrm{NS}$ \\
$\begin{array}{l}\text { Angle for crouch gait } \\
\text { Severe }\end{array}$ & $25(83.3)$ & $25(83.3)$ & $26(86.7)$ & $(\mathrm{P}<0.05)$ \\
Moderate & $6(24.0)$ & $2(8.0)$ & $1(4.0)$ & $\mathrm{X} 2=10.47$ \\
Mild & $13(52.0)$ & $21(84.0)$ & $22(88.0)$ & $\mathrm{P}=0.033 \mathrm{~S}$ \\
None & $6(24.0)$ & $2(8.0)$ & $2(8.0)$ & $(\mathrm{P}<0.05)$ \\
Foot contact & $0(0.0)$ & $0(0.0)$ & $0(0.0)$ & \\
Toe & & & & \\
Toe-heel & $24(80.0)$ & $0(0.0)$ & $4(13.3)$ & $\mathrm{X} 2=92.64$ \\
$\begin{array}{l}\text { Flat } \\
\text { Occasional heel-toe }\end{array}$ & $5(16.7)$ & $6(20.0)$ & $24(80.0)$ & $\mathrm{P}<0.00001 \mathrm{~S}$ \\
\hline
\end{tabular}

*Figure within parenthesis indicates percentage.

improvement, with most of the severe and moderate angle for crouch gait at baseline changed to mild a few to none $(p<0.001)$. Changes in knee recurvatum were not significant as very few children had knee recurvatum $>5$ or $<0-5$ $(\mathrm{p}=0.688)$. During measuring crouch, the patient's baseline scores were $24 \%$ and $52 \%$ respectively and at 1 st month scores were $0 \%$ and $52 \%$. change more significantly. In this study most of the children having foot contact with their toes at baseline change $(80 \%$ of the children at baseline had foot contact with their toes, but at 6 months of evaluation $80 \%$ showing flat foot $)$. The change was more $(p<0.001)$. In gross motor function level, most of the children changed from level 5 gross motor function to level 4 and a few to level 3 and level $2(p<0.001)$ which indicate better

Table 4: Gross Motor Functional Classification System is stable in liquid form, but can only be given enterally (except if given intrathecally). Baclofen cannot be given intravenously and is not absorbed rectally ${ }^{17}$. Children can have similar withdrawal symptoms as in adults, which includes hallucinations and seizure ${ }^{18}$. The usually starting dose is $2.5 \mathrm{mg}$ a day and titrated up every 3-5 days to a maximum of $20-60 \mathrm{mg}$. per day ${ }^{19}$. In a study of infants receiving physical therapy, Scherzer et al noted improvement in broadly defined motor and social skills and in the patient's ability to address the children's daily needs, but could not separate the influences of age, therapy and cognitive level ${ }^{13}$.

In the study in Norway to assess the effects of intensive physiotherapy in cerebral palsy. A single-subject design was used. Intervention consisted of two 4-week periods of daily

\begin{tabular}{lllll}
\hline $\begin{array}{l}\text { Gross Motor } \\
\text { Function }\end{array}$ & Pre treatment & $\begin{array}{l}\text { 3 Month after } \\
\text { treatment }\end{array}$ & $\begin{array}{l}\text { 6 Month after } \\
\text { treatment }\end{array}$ & $\begin{array}{l}\text { Chi Square test; } \\
\text { P value }\end{array}$ \\
\hline Level1 & $0(0.0)$ & $0(0.0)$ & $1(3.3)$ & $\mathrm{X} 2=14.14$ \\
Level2 & $1(3.3 \%)$ & $1(3.3)$ & $1(3.3)$ & $\mathrm{P}=0.028 \mathrm{~S}$ \\
Level3 & $0(0.0)$ & $0(0.0)$ & $0(0.0)$ & $(\mathrm{P}<0.05)$ \\
Leve14 & $3(10.0 \%)$ & $6(20.0)$ & $14(46.7)$ & \\
Leve15 & $26(86.7 \%)$ & $23(76.7)$ & $14(46.7)$ & \\
\hline
\end{tabular}


physiotherapy, interrupted by 8 weeks of physiotherapy as usual. The children were assessed every 4 th week using the Gross Motor Function Measure. Results were visually analyzed, and statistical significance of Gross Motor Function Measure-66 scores was established with the 2 SD band method. Compliance was high. All infants showed gross motor progress compared with baseline, but separating effect of daily physiotherapy from physiotherapy as usual was inconclusive. Parents preferred the intensive treatment alternative. Blocks of intensive therapy can be an alternative to regular dosage of physiotherapy, but until further studies are conducted, the physiotherapy intervention, intensity, and frequency should be tailored to meet the needs of each individual infant and family ${ }^{20}$. Analytical findings of this study showed that combined baclofen and intensive rehabilitation is more beneficial to decrease stiffness and spasm and thereby improving movement in a young child with cerebral palsy.

\section{Conclusion}

Analytical results of this study shows that basic motor abilities and self-care improved after intensive physiotherapy with baclofen is effective for reducing generalized spasticity regarding muscle tone and joint angle stiffness and gait improvement in cerebral palsy patients.

\section{References}

1. Rosenbaum P, Paneth N, Leviton A, A report: the definition and classification of cerebral palsy April 2006. Dev Med Child Neurol 2007;109:8-14.

2. Thomas MO. Diagnosis Treatment and prevention of cerebral palsy. Clinical Obstetrics Gynaecology, 2008: 514, 816-828

3. Surveillance of Cerebral Palsy in Europe (SCPE). Surveillance of cerebral palsy in Europe: a collaboration of cerebral palsy surveys and registers. Dev Med Child Neurol. 2000;42(12): 816-824.

4. Reddighough DS, Collins KJ. The epidemiology and causes of cerebral palsy. Aust J Physiother. 2003; 49(1):456-462.

5. Khan MSZ. A study on patients with cerebral palsy attending Physical Medicine Department of BSMMU. Bangladesh Med Res Counc Bull 1998, 50-52.
6. Tal KC, Tal J, Aviva FV. Upper Extremity Function and Occupational Performance in Children with Spastic Cerebral Palsy Following Lower Extremity BotulinumToxin Injections. Child Neurology,2010;25(6):694-700 7. Yam WK, Leung MS .Interrater Reliability of Modified Ashworth Scale and Modified Tardieu Scale in Children With Spastic Cerebral Palsy. J Child Neurol .2006 ; 21: 1031-1035.

8. Katz RT:Management of spastic hypertonia after stroke. J Neurol Rehabil 1991;5:s5-s12.

9. Tordis U, Anne BS, Anne EL. Effects of intensive physiotherapy in infants newly diagnosed with cerebral palsy. Pediatr Phys Ther 2009;21:140-149

10. Rosenbaum P, Dan B, Leviton A, Paneth N, Jacobsson B, Goldstein M,Baxm. Proposed definition and classification of cerebral palsy. Dev. Med. Child Neurol, 2005;47:471-576.

11. Milla PJ, Jackson AD, Acontrolled trial of baclofen in children with cerebral palsy. J Int Med Res 1977;5:398-440

12. Wright T, Nicholson J. Physiotherapy for the specific child: An evaluation. Dev Med Child Neurol, 1973;15:146-63.

13. Scherzer AL, Mike V, Llpon J. Physical therapy as a determinant of change in the cerebral palsied infant. Pediatrics, 1976;58: 47-52.

14. Christiansen AS, Lange C. Intermittent versus continuous physiotherapy in children with cerebral palsy. Dev Med child Neurol, 2008; 50:290-293.

15. Whyte, J and Robinson, K . Pharmacologic Management. The Practical Management of spasticity in Children and Adults. Philadelphia, Lea and Febiger.1990: 209.

16. Stempien, L and Gaebler-Spira, D . Rehabilitation of Children and Adults with Cerebral Palsy.Physical Medicine and Rehabilitation. R. L. Braddom. Philadelphia, WB Saunders.1996:1113-1132.

17. Kriel, R, Krach, L, Hoff, D, Gormley, M and Jones-Saete, C . Failure of Absorption of After Rectal Administration. Pediatr Neurol 1997;16(4): 351-352.

18. Reisman, M and BM, G. Hallucinations association with acute baclofen withdrawal: report of two pediatric cases. Kansas City, MO, 47th Annual Assembly of the American Academy of Physical Medicine and Rehabilitaiton.1997,.

19. Gracies, J, P, N, Elovic, E, McGuire, J and Simpson, D . Traditional Pharmacological Treatments for Spasticity Part II: General and Regional Treatments. Muscle Nerve 1997; S 6:100.

20. Pellegrino L. Cerebral palsy. In ML Batshow; ed., children with disabilities, Baltimore; Paul H. Brookes publishing. 4th ed. Pp. 499-528 